International Journal of Medical Arts 2020; 2 [2]: 436-441.

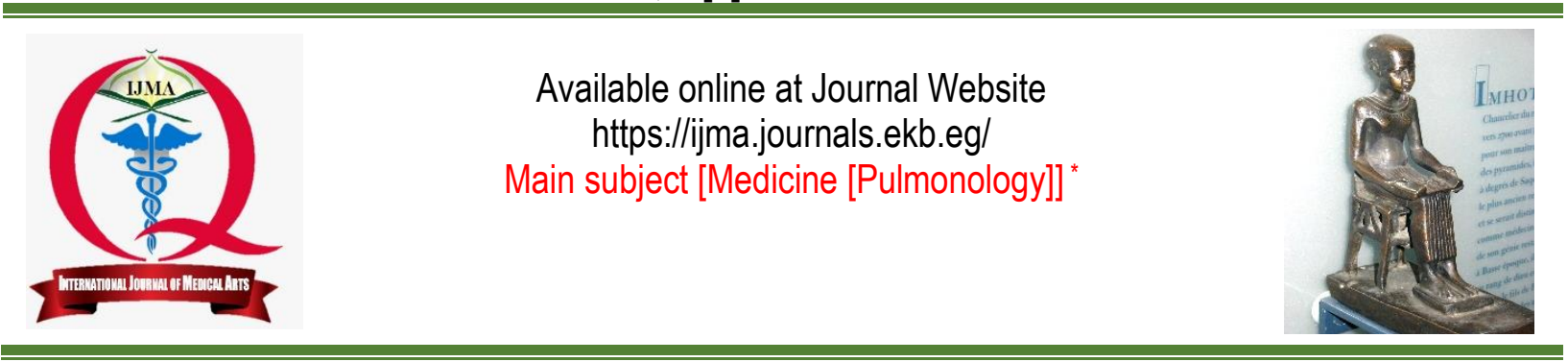

Original article

\title{
Effects of Bariatric Surgery on Indices of Obstructive Sleep Apnea and Pulmonary Function Tests
}

\author{
Atef Wahdan Alrifaia ; Mostafa Samaha Samaha ${ }^{\mathbf{a}} ;$ Hassan Aref $^{\mathbf{b}}$ \\ Department of Chest Disease, Damietta Faculty of Medicine, Al-Azhar University, Egypt[a]. \\ Department of Chest Disease, Faculty of Medicine, Cairo University, Egypt ${ }^{[b]}$. \\ Corresponding author: Atef wahdan Alrifai \\ Email: atefchest@domazhermedicine.edu.eg
}

Received at: July 13, 2019; Revised at: February 17, 2020; Accepted at: March 24, 2020; Available online at: March 24, 2020

DOI: 10.21608/ijma.2020.14786.1019

\section{ABSTRACT}

Background: Obesity reaches the epidemic situation. Obstructive sleep apnoea is a major concern in obese patients.

Aim of the work: To analyse apnoea hypopnea index and to evaluate changes in pulmonary functions before and after bariatric surgery in obese patients.

Patients and Methods: We identify 160 patients who met our inclusion criteria. However, 121 patients returned for follow up evaluation. They were 98 women and 23 men. 84 had Raux-en-Y gastric bypass and 37 had sleeve gastrectomy. They were subjected to full history taking, clinical examination, objective measures of obstructive sleep apnoea [apnoea hypopnea index, body mass index, mean oxygen saturation, low oxygen saturation, nasal continuous positive airway pressure and Pulmonary function tests]. In addition, all patients were submitted to a sleep study.

Results: Statistically significant improvement was obtained postoperative for apnoea hypopnea index, body mass index, nasal continuous positive airway pressure requirement, mean oxygen saturation and low oxygen saturation. The spirometry and lung volume finding showed statistically significant improvement in lung function parameters after surgery. There was a significant positive correlation between body mass index and apnoea hypopnea index, with significant negative correlation between body mass index and forced vital capacity.

Conclusion: Bariatric surgery is associated with significant improvement in pulmonary functions and obstructive sleep apnoea indices.

Keywords: Obstructive sleep apnea; Pulmonary functions; Obesity; Gastric bypass; Sleeve gastrectomy.

This is an open access article under the Creative Commons license [CC BY] [https://creativecommons.org/licenses/by/2.0/]

Please cite this article as: Alrifai AW, Samaha MS, Aref H. Effects of Bariatric Surgery on Indices of Obstructive Sleep Apnea and Pulmonary Function Tests. IJMA 2020; 2[2]: 436-441.

* Main subject and any subcategories have been classified according to researchers' main field of study. 


\section{INTRODUCTION}

Obstructive sleep apnea [OSA] is a common condition in morbidly obese patients with prevalence ranging from $12-78 \%\left[{ }^{[1]}\right.$.

Tow percent of middle-aged women and $4 \%$ of middle-aged men have obstructive sleep apnea, a condition linked to obesity [2]. Weight loss improves symptoms associated with OSA[3].

Although, physicians advocate weight loss to their patients. However, only a minority of patients maintain their attained diet-weight reduction and only $3 \%$ of patients with OSA, who had a marked improvement in their sleep apnoea symptoms as a consequence of diet-weight reduction, maintained their weight after 5 years. However, many patients regained and even exceeded their baseline weight ${ }^{[4]}$.

Bariatric surgery may help these morbidly obese patients. Gastric bypass [GB] surgery has confirmed to be an effective procedure used to reduce body mass index $[\mathrm{BMI}][5]$.

GB has been shown to be an effective modality to help treat OSA[6].

A little data exists concerning long-term result of GB induced weight reduction on indices of OSA[7].

Obesity also exerts important and complex effects on the respiratory system, excessive body weight may lead to impairment in the respiratory function and can cause a restrictive or an occasionally an obstructive pulmonary disorder [8.9].

We hypothesize that in morbidly obese patients, marked weight reduction obtained by bariatric surgery would offer an effective improvement in pulmonary functions and sleep quality.

\section{AIM OF THE WORK}

The purpose of this study was to analyze apnea hypopnea index [AHI], one year after bariatric surgery and evaluate the changes in pulmonary function tests before and after bariatric surgery in obese patients

\section{PATIENTS AND METHODS}

A list of patients who underwent Raux-en-Y GB and sleeve gastrectomy surgery was referred to sleep disorders center and pulmonary function test laboratory to identify patients who had been received a diagnosis of OSA during preoperative assessment.

We identified 160 patients who met our criteria, and 121 patients returned for follow up evaluation.

\section{Inclusion criteria:}

Patients with the following criteria were included in the study: 1] Morbid obesity with BMI between $40-60 \mathrm{~kg} / \mathrm{m}^{2} ; 2$ ] Diagnosis of OSA prior to surgery with split-night polysomnography and prescription of nasal continuous positive airway pressure [CPAP]; 3] Split-night polysomnography "defined as combined diagnostic and CPAP titration study during same night" and 4] Patients at least 18 years of age.

\section{Exclusion criteria:}

On the other side, patient with one or more of the following were excluded from the study: 1] Any active malignancy; 2] Active alcohol or drug abuse; 3] Dementia or treatment refractory psychotic disease leading to inability to provide informed consent; 4] Use of medications that may interfere with the sleep structure; 5] History of chronic or active lung disease.

All patients provided an informed consent after full explanation of the study aim and its methods, before joining the study and before surgery.

In addition, the study protocol was approved by the local ethics and research committee of International Medical Canter [Jeddah, KSA] and AlAzhar Faculty of Medicine [Damietta].

A 121 patients returned for follow up testing and were included in the subsequent analysis. They were 98 females and 23 males.

They were subjected to full history taking, clinical examination, objective measures of OSA [AHI, BMI, mean oxygen saturation, low oxygen saturation, nasal CPAP] and Pulmonary function tests. In addition, all patients were submitted to a sleep study as the following.

\section{Sleep study:}

Patients underwent split-night polysomnography during one night of sleep disorders before and after surgery and at least one year postoperative using Philips Respironics Alice 6 system [Royal Philips Electronics, USA, www.philips.com/ healthcare]. Patients attended the sleep disorders centre 
two hours before their usual bedtime. Technicians attached transducers to measure: electroencephalogram [EEG] [central and occipital leads]; Electrooculography [left and right eyes]; electrocardiogram [ECG [V2]; Electromyography [geniohyoid, intercostal, and anterior tibialis] activities; measurement of nasal-oral airflow using a thermistor and oxygen saturation using a pulse oximeter. Sleep stages were visually scored in 30second epochs. Each polysomnography [PSG] recording was analyzed manually.

Apnea was scored when air flow ceased for 10 s or longer. Hypopnea was recorded when the airflow was below $50 \%$ for at least 10 s followed by $>3 \%$ oxyhemoglobin desaturation. The apnea/ hypopnea index [AHI] was calculated as the number of [apnea thypopnea] episodes/hour of sleep time. Patients with an AHI more $>20$ were titrated to CPAP during split-night polysomnography.

In addition to apnea criteria, patient needed a minimum of 180 minutes of recording time and a period of rapid eye movement sleep, if no rapid eye movement sleep [REMS] occurred, titration begin after $180 \mathrm{~min}$ and an oxygen desaturation of $<85 \%$. The CPAP pressure started at $5 \mathrm{cmH}_{2} \mathrm{O}$ and increase by $2.5 \mathrm{~cm} \mathrm{H}_{2} \mathrm{O}$ increment every $15 \mathrm{~min}$. In order to eliminate snoring and any remaining upper airway resistance syndrome [URRS] activity

\section{Pulmonary function tests:}

Pulmonary function tests [PFTs] were performed before and at least one year after bariatric surgery. The PFTs were performed using Geratherm Respiratory Spirometry [Geratherm Respiratory GmbH Sparkassen passage 197688 Bad Kissingen GERMANY] and Plethysmography.

All tests had been performed according to the recommendations of the American Thoracic Society /European Respiratory Society.

Each participant had been performed 3 tests [with 2 reproducible and acceptable maneuvers] in the setting position with a nose clip in place. The measurement included the forced vital capacity [FVC], forced expiratory volume in the first second [FEV1], FEV1/FVC \%, residual volume and total lung capacity.
Statistical analysis of data: The collected data were collected in an excel sheet, then coded and analysed by statistical package for social science [SPSS] version 16 [SPSS Inc., Chicago, USA]. Numerical data were expressed as mean and standard deviation and groups compared by student [t] test, while qualitative data were expressed as number and percent distribution and groups were compared by $C$ hi square test. $P$ value $<0.05$ was the cut-off for statistical significance.

\section{Results}

In the present work, 121 patients were evaluated with split-night poly-somnography and pulmonary function tests [spirometry and lung volumes] preoperative and at $19+3.5$ months postoperatively, 98 women [81\%] and 32 men [19\%]. 84 patients had Raux-en-Y GB and 37 patients had sleeve gastrectomy. Age, BMI and AHI preoperative were $41+10,51+9$ and $53+21$ respectively.

Using the parametric paired T-test, statistically significant improvement was obtained postoperative for AHI, BMI, nasal CPAP pressure requirement, mean oxygen saturation and low oxygen saturation $[\mathrm{p}<0.05]$ with mean reduction of $\mathrm{AHI}$ by $72 \%$, decreasing the $\mathrm{AHI}$ by $40+31$ events per hour, mean reduction of BMI by $32 \%$ decreasing BMI by $17+9$. Mean nasal CPAP requirement was reduced in $83 \%$ of patients and 70 of 121 patients no longer need nasal CPAP [57\%] and 30 patients [24\%] show significant reduction of CPAP pressure. The mean oxygen saturation improved by $3 \%$, the low oxygen saturation improved by $16 \%$ from $75 \%$ to $91 \%$. The values of pulmonary function tests before and after surgery can be seen in the table [1].

The spirometry and lung volume finding were expressed in absolute values and as a percentage of predicted values and shows statistically significant improvement in lung function parameters after surgery. The patients then divided to responders $[\mathrm{BMl}<30] 75$ patients and non-responders [BMI >30] 46 patients table [2], and using parametric paired Ttest show statistically significant improvement of studied parameters as shown in the table [2]. There was a significant positive correlation between BMI and $\mathrm{AHI}$, and significant negative correlation between $\mathrm{BMI}$ and $\mathrm{FVC} \%$. 
Table [1]: Patients characteristic data [ $n=121]$

\begin{tabular}{|c|c|c|c|}
\hline Variables & Preoperative & Follow up & $P$ value \\
\hline Age at time of surgery, years $\pm S D$ & $41.60 \pm 10.65$ & & \\
\hline Sex [males, females] & 23 males, 98 females & & \\
\hline Weight $[\mathrm{Kg}] \pm \mathrm{SD}$ & $125.35 \pm 21.65$ & $88.60 \pm 16.35$ & $<0.05$ \\
\hline $\mathrm{BMl}\left[\mathrm{kg} / \mathrm{m}^{2}\right] \pm \mathrm{SD}$ & $51.50 \pm 9.35$ & $35.75 \pm 10.50$ & $<0.05$ \\
\hline $\mathrm{AHI}$ & $53 \pm 21$ & $13 \pm 9$ & $<0.05$ \\
\hline $\begin{array}{l}\text { Type of surgery } \\
\text { Gastric Bypass } \\
\text { Sleeve gastrectomy }\end{array}$ & $\begin{array}{l}84 \\
37\end{array}$ & & \\
\hline sleep study after surgery [days] & $580.16 \pm 106.5$ & & \\
\hline Pretest $\mathrm{O}_{2}$ saturation $\%$ & $96.5 \pm 2.2$ & $97.1 \pm 1.9$ & $<0.05$ \\
\hline Mean $\mathrm{O}_{2}$ saturation $\%$ & $94.5 \pm 3.2$ & $97.4 \pm 2.7$ & $<0.05$ \\
\hline Low $\mathrm{O}_{2}$ saturation & $75.5 \pm 7.4$ & $91.2 \pm 3.7$ & $<0.05$ \\
\hline CPAP pressure required & $9.5 \pm 2.5$ & $4.5 \pm 3.5$ & $<0.05$ \\
\hline Sleep time below $90 \% \mathrm{O}_{2}$ saturation [min] & $138.4 \pm 92.6$ & $48.8 \pm 15.8$ & $<0.05$ \\
\hline \multicolumn{4}{|l|}{ PFT } \\
\hline FEV1 [L] & $2.81 \pm 0.62$ & $2.97 \pm 0.55$ & $<0.05$ \\
\hline FEV1\% of predicted & $79.6 \pm 13.4$ & $94.5 \pm 7.5$ & $<0.05$ \\
\hline FVC [L] & $3.75 \pm 0.73$ & $3.93 \pm 0.92$ & $<0.05$ \\
\hline FVC $\%$ of predicted & $81.5 \pm 11.5$ & $95.6 \pm 10.7$ & $<0.05$ \\
\hline FEV1/FVC \% & $80.5 \pm 6.6$ & $81.6 \pm 5.7$ & 0.35 \\
\hline TLC [L] & $5.93 \pm 1.4$ & $6.43 \pm 1.2$ & $<0.05$ \\
\hline TLC [\% of predicted] & $75.4 \pm 11.5$ & $84.5 \pm 10.5$ & $<0.05$ \\
\hline $\mathrm{RV}[\mathrm{L}]$ & $1.56 \pm 0.7$ & $1.71 \pm 0.8$ & $<0.05$ \\
\hline RV [\% of predicted] & $80.35 \pm 9.5$ & $95.1 \pm 10.3$ & $<0.05$ \\
\hline
\end{tabular}

$P$ value $<0.05$ indicates significant difference

Table [2]: data of responders versus non-responders after 1 year

\begin{tabular}{|l|c|c|c|}
\hline \multicolumn{1}{|c|}{ Variables } & responders & Non-responders & P value \\
\hline Age at time of surgery, years \pm SD & $35.20 \pm 4.25$ & $40.50 \pm 11.50$ & $<0.05$ \\
\hline Sex [males, females] & 18 males, 63 females & 5 males, 35 females & \\
\hline Weight $[\mathrm{Kg}] \pm$ SD & $92.50 \pm 16.40$ & $105.40 \pm 18.20$ & $<0.05$ \\
\hline BMI $\left[\mathrm{kg} / \mathrm{m}^{2}\right] \pm$ SD & $27.20 \pm 3.35$ & $35.35 \pm 5.50$ & $<0.05$ \\
\hline AHI & $3.5 \pm 2.1$ & $14 \pm 4.5$ & $<0.05$ \\
\hline Mean $\mathrm{O}_{2}$ saturation during sleep \% & $96.5 \pm 2.2$ & $93.4 \pm 2.5$ & $<0.05$ \\
\hline Low $\mathrm{O}_{2}$ saturation during sleep\% & $90.15 \pm 5.7$ & $84.6 \pm 4.6$ & $<0.05$ \\
\hline Patient need for CPAP $[\%]$ & & & $<0.05$ \\
\hline CPAP pressure required & 0 & $4.5 \pm 3.5$ & \\
\hline PFT & & & $<0.05$ \\
\hline FEV1 [L] & $2.93 \pm 0.32$ & $2.73 \pm 0.75$ & $<0.05$ \\
\hline FEV1\% of predicted & $97.6 \pm 13.4$ & $85.5 \pm 7.5$ & $<0.05$ \\
\hline FVC [L] & $3.97 \pm 0.55$ & $3.63 \pm 0.92$ & $<.06$ \\
\hline FVC \% of predicted & $98.5 \pm 7.5$ & $82.6 \pm 7.7$ & $<0.05$ \\
\hline FEV1/FVC \% & $78.5 \pm 6.6$ & $81.6 \pm 5.7$ & $<0.05$ \\
\hline TLC [L] & $6.63 \pm 1.4$ & $5.43 \pm 1.4$ & $<0.05$ \\
\hline TLC [\% of predicted] & $90.4 \pm 4.5$ & $80.5 \pm 6.5$ & $<0.05$ \\
\hline RV [L] & $1.74 \pm 0.7$ & $1.62 \pm 0.8$ & \\
\hline RV [\% of predicted] & $97.35 \pm 9.5$ & $85.1 \pm 6.3$ & \\
\hline
\end{tabular}

$P$ value $<0.05$ indicates significant difference 


\section{DISUCSSION}

Main findings of this study are that obese patients with obstructive sleep apnea who underwent bariatric surgery had marked improvement of sleep apnea indices, BMl and many had discontinuation of their CPAP therapy within $19+3.5$ months of surgery, we have only 21 patients out of 121 patients who did not show significant improvement of $\mathrm{AHI}$, and this may be due high initial BMI

Obstructive sleep apnea results from upper airway collapse that which leads to ineffective respiratory efforts during sleep. The occlusion of the upper airway structures is secondary to the excessive fatty tissue and its laxity, a condition that is characteristic in the morbidly obese. Resolution of sleep apnea is linked to improvement in the upper airway passage associated with weight reduction and loss of the upper airway fatty tissue ${ }^{[10]}$.

Compliance with CPAP can be problem, thus the reduction or resolution of the need for CPAP has positive personal implication for patients requiring CPAP for OSA ${ }^{[3,9] \text {. }}$

In the present study, we found that $\mathrm{AHI}$ reduced postoperatively by $72 \%$, and these confirm the study of Gionmattia et al. ${ }^{[11]}$ who evaluated the impact of sleeve gastrectomy on upper respiratory physiology in the long term [5 years] and they showed that $\mathrm{AHI}$ improved in $80.6 \%$ of patients after surgery and the other $19.4 \%$ of patients without improvement in $\mathrm{AHI}$ all had a respiratory resistance due to nasal obstruction. Also, our study correlate with study done by Myura et al. ${ }^{[12]}$ who study self-report remission of OSA following bariatric surgery and they found that self-reported OSA remission rate was $60 \%$, one year after surgery.

As current study, Lankford and colleagues reported a significant reduction in overall CPAP pressure after Roux en- $Y$ gastric bypass ${ }^{[0]}$. Similarly, Haines et al. reported that in a group of patients with sleep apnea and on CPAP, at a median of 11 months after bariatric surgery, only [37\%] patients were still on CPAP therapy ${ }^{[13]}$.

Because sleep apnea is known to be associated with intermittent hypoxia and increased risk for heart failure and pulmonary hypertension, improvement of sleep apnea symptoms after gastric bypass may reduce the risk for cardiopulmonary dysfunction in high-risk, morbidly obese subjects[14].
Obesity can impair pulmonary functions and decrease exercise capacity due to its adverse effects on respiratory mechanics, respiratory muscle strength, lung volumes, work of breathing and gas exchange ${ }^{[15]}$.

In the present study we found a significant improvement of respiratory functions after surgery in obese patients. These results are correlated with Wei et al.[16] who studied anthropometric parameters and pulmonary function tests in 94 patients after bariatric surgery and show significant decrease of anthropometric parameters and improvement of pulmonary function tests three months after surgery, and found that reduction in waist circumference [WC] correlate significantly with increase in FEV1 and FVC.

Also our study agree with Aguiar et al.[17] who studied 16 patient underwent bariatric surgery, 90 days after surgery and showed mean BMl reduced from $48.15+8.58$ to $36.91+6.67 \mathrm{~kg} / \mathrm{m}^{2}$, significant difference between preoperative and postoperative period regarding neck and waist circumference, maximum inspiratory and maximum expiratory pressure, significant improvement of FVC and FEV1 and significant reduction of $\mathrm{AHI}$ after surgery $15.65+15.51$ to $6.26+7.57$ event/hour. Also, Gabrielsen et al. ${ }^{[18]}$ study pulmonary function tests and blood gases after gastric bypass in 76 patients after one year of surgery, they showed that improvement in pulmonary function tests and blood gases were significantly greater after surgery than after lifestyle intervention.

In the present study we divided the patients into responders [BMl $\left.<30 \mathrm{~kg} / \mathrm{m}^{2}\right] 75$ patients and nonresponders [BMl $\left.>30 \mathrm{~kg} / \mathrm{m}^{2}\right] 46$ patients, and in comparison, between two groups we found more improvement in $\mathrm{BMI}, \mathrm{AHI}$ and pulmonary functions in responder group, this may be due to younger age and lower initial BMI.

Despite our best efforts, many potential participants did not return for repeat polysomnography and PFTs, we considered possible reasons for subjects who did not return for repeat tests. This could be due to time factor [they want not to miss their work], the adequacy of insurance coverage and some show subjective improvement and did not believe re-evaluation was necessary. 
The limitation of our study: majority of patients were females in whom lesser effects on lung functions are expected due fat distribution in the female body. In our clinical practice, we found that patients regain weight by time after surgery so we recommend long-term study of pulmonary functions and polysomnography after surgery.

Financial and Non-Financial Relationships and Activities of Interest

None

\section{REFERENCES}

1. Lankford DA, Proctor CD, Richard R. Continuous positive airway pressure [CPAP] changes in bariatric surgery patients undergoing rapid weight loss. Obes Surg 2005; 15: 336-41. [DOI: 10.1381/ 0960892053576749].

2. Young T, Palta M, Dempsey J, Skatrud J, Weber S, Badr S. The occurrence of sleep-disordered breathing among middle-aged adults. N Engl J Med 1993; 328: 1230-1235. [DOI: 10.1056/NEJM199304293281704].

3. Loube DI, Loube AA, Mitler MM. Weight loss for obstructive sleep apnea: the optimal therapy for obese patients. J Am Diet Assoc 1994; 94:1291-1295. [PMID: 7963174].

4. Guilleminault C. Treatment in obstructive sleep apnoea. In: Guilleminault C, Partinen M, eds. Obstructive sleep apnea syndrome: clinical research and treatment: New York, NY: Raven Press, 1990;99-127

5. Coutant R, Bouhours-Nouet N, Donzeau A, Fauchard M, Decrequy A, Malka J, et al. Bariatric surgery in adolescents with severe obesity: Review and state of the art in France. Ann Endocrinol [Paris]. 2017 Oct;78[5]:462468. [DOI: 10.1016/j.ando.2017.03.002].

6. Simard B, Turcotte H, Marceau P, Biron S, Hould FS, Lebel S, Marceau S, Boulet LP. Asthma and sleep apnea in patients with morbid obesity: outcome after bariatric surgery. Obes Surg. 2004;14[10]:1381-8. [DOI: 10.1381/ 0960892042584021]

7. Salord N, Mayos M, Miralda R, Perez A. Respiratory sleep disturbances in patients undergoing gastric bypass surgery and their relation to metabolic syndrome. Obes Surg. 2009 Jan;19[1]:74-9. [DOI: 10.1007/s11695-0089670-0].

8. Dhabuwala MB, Cannan RJ, Stubbs RS. Improvement in co-morbidities following weight loss from gastric bypass surgery. Obes Surg 2000; 10:428-435. [DOI: 10.1381/ 096089200321594291].
9. Epstein LJ, Kristo D, Strollo PJ Jr, Friedman N, Malhotra A, Patil SP. Outcome evaluation of long-term nasal continuous positive airway pressure therapy in obstructive sleep apnea. Am J Ther 1999; 6:293-297. [PMID: 11329112].

10. Esteban J, Macelo W, Ninh T. Resolution of obstructive sleep apnoea after laparoscopic gastric bypass. Obes Surg. 2007; 17:1279-1282. [DOI: 10.1007/s11695-0079228-6]/

11. Gianmattia D, Paolo L, Federica D, Motta G, Docimo L, Testa D. Sleeve gastrectomy improve obstructive sleep apnoea syndrome [OSAS]:5-year longitudinal study. Surg Obes Relat Dis. 2016; 12:70-74. [DOI: 10.1016/j.soard. 2015.02.020].

12. Myura N, Arthur M, Daniel B, Genaw JA, Hawasli AA, Birkmeyer NJ, et al. Self-reported remission of obstructive sleep apnea following bariatric surgery: cohort study. Surg Obes Relat Dis. 2015; 11:697-703. [DOI: 10.1016/j.soard.2014.10.011].

13. Haines KL, Nelson LG, Gonzalez R, Torrella T, Martin $\mathbf{T}$, Kandil $\mathbf{A}$, et al. Objective evidence that bariatric surgery improves obesity-related obstructive sleep apnea. Surgery 2007; 141: 354-8. [DOI: 10.1016/j.surg. 2006. 08.012].

14. Sidana J, Aronow WS, Ravipati G, Di Stante B, McClung JA, Belkin RN, Lehrman SG. Prevalence of moderate or severe left ventricular diastolic dysfunction in obese persons with obstructive sleep apnea. Cardiology 2005; 104: 107-9. [DOI: 10.1159/000087128].

15. Koenig SM. Pulmonary complications of obesity. Am J Med Sci. 2001; 321:249-79. [PMID: 11307867].

16. Wei YF, Tseng WK, Huang CK, Tai CM, Hsuan CF, Wu HD. Surgically induced weight loss, including reduction in waist circumference, is associated with improved pulmonary function in obese patients. Surg Obes Relat Dis 2011,7[5]:599-604. [DOI: 10.1016/j.soard.2011.04.221].

17. Aguiar IC, Freitas WR, Santos IR, Apostolico N, Nacif SR, Urbano JJ, et al. Obstructive sleep apnea and pulmonary function in patients with severe obesity before and after bariatric surgery: a randomized clinical trial. Multidisciplinary Respir Med. 2014; 9[1]:43. [DOI:10.1186/ 2049-6958-9-43].

18. Gabrielsen AM, Lund MB, Kongerud J, Viken KE, Røislien J, Hjelmesaeth J, Hofso D. Pulmonary function and blood gases after bariatric bypass and lifestyle intervention: a comparative study. Clin Obes. 2013; 3:11123. [DOI: 10.1111/cob.12024]. 